EDITORIAL

\title{
As veias abertas do planejamento educacional no Brasil*
}

Donaldo Bello de Souza ${ }^{\text {a }}$

\begin{abstract}
Princípio [...] é algo diferente de origem. O início é histórico e dá aos vindouros um número crescente de pressupostos constituídos pela elaboração intelectual já realizada. Origem, porém, é a fonte de onde dimana o impulso do filosofar. É este que confere sentido a cada uma das filosofias vigentes e que permite entender as filosofias anteriores (JASPERS, 1987, p. 17).
\end{abstract}

Resguardadas as devidas proporções e, sobretudo, as distinções entre o saber filosófico e o científico, Karl Jaspers nos inspira a uma dupla compreensão sobre o ato de planejar. Do ponto de vista de sua origem, o planejamento poderia emergir da imperiosa necessidade humana de prever, antecipar e elaborar (FUENTES PÉREZ, 1986; RUBIO MAYORAL, 1996), como também do enfrentamento da escassez de recursos necessários ao atingir de determinados objetivos (DÍEZHOCHLEITNER, 1990), primitivamente se manifestando por meio de uma ação prática, à margem de certo arcabouço teórico (KHÔI, 1992). Já em relação ao seu início, especificamente no campo educacional, a história sinaliza que o planejamento da Educação teria surgido a partir dos primeiros planos quinquenais de planificação econômica da então União Soviética, entre o limiar da década de 1920 e os anos 1930 (KHÔI, 1992), se difundido no ocidente em meio à expansão da escola de massas (MEYER; RAMÍREZ; SOYSAL, 1992), e vindo a se constituir numa área de conhecimento da Educação em tempos relativamente recentes, embora já institucionalizado em muitos países pari passu ao valimento social, acadêmico e científico da administração/gestão dos sistemas de ensino e das instituições escolares (PALMERO CÁMARA; JIMÉNEZ EGUIZABAL, 1986).

No Brasil, é sabido que nas décadas iniciais do século XX a importância do planejamento da Educação será científica e estrategicamente exaltada no Manifesto dos Pioneiros da Educação, em 1932, para, logo em seguida, configurar-se enquanto Projeto de Lei (PL) de um Plano Nacional de Educação (PNE) elaborado pelo

\footnotetext{
Com o justo desvelo, toma-se aqui emprestado parte do título da importante obra de Eduardo Galeano, "As veias abertas da América Latina" (cf. Galeano, 1987).

a Universidade do Estado do Rio de Janeiro, Rio de Janeiro, RJ, Brasil.
} 
Conselho Nacional de Educação (CNE), em 1937, e abandonado pelo Estado Novo (1937-1946) (CURY, 2009; HORTA, 1982; SAVIANI, 1999; 2010). Mas será nos primeiros anos da década de 1960, agora no âmbito do então Conselho Federal de Educação (CFE), que se erige um primeiro PNE, em 1962, descartado, no ano posterior, em face da formulação do Plano Trienal de Educação (19631965), oficialmente denominado por "pré-investimento para aperfeiçoamento do fator humano" (BORDIGNON, 2014, p. 44). Ao longo da ditadura militar no país (1964-1985), e já com este Plano Trienal também desarrimado, a hegemonia tecnocrática passa a modular o planejamento da Educação segundo uma lógica econométrica e financeira, pautando, com isto, os Planos Nacionais de Desenvolvimento Econômico e Social e sua associação a três Planos Setoriais de Educação e Cultura (PSEC) (1972-1974, 1975-1979 e 1980-1985). Neste momento, o CFE não mais protagoniza a elaboração destes planos de Educação, agora de autoria de técnicos do Instituto de Pesquisa Econômica Aplicada (Ipea), coerentemente ao nacional-desenvolvimentismo em vigor (BORDIGNON, 2014; SAVIANI, 1999; VIEIRA, 2014).

O enfoque economicista sobre o planejamento da Educação ainda viria a persistir nos primeiros anos da redemocratização do Brasil, neste momento, em 1985, por meio do plano "Educação para Todos: Caminho para Mudança" (VIEIRA, 2014). Mas os ecos relacionados a novos enfoques sobre o planejamento da Educação viriam a desembarcar no país somente no início dos idos de 1990, em que pese o fato de terem internacionalmente surgido nos anos 1970. Em meio à diversificação dos atores e dos organismos responsáveis pela Educação, o planejamento da Educação viria a adquirir um leque amplo de ressignificações em diversos países ocidentais, especialmente a partir da difusão do chamado modelo de planejamento da Educação pautado na demanda social (WEILER, 1992). Este modelo, entre outras dimensões, passa a atribuir centralidade aos processos participativos e à ampliação dos atores sociais envolvidos na elaboração, execução e avaliação dos planos de Educação, agora não mais de exclusividade das tecnocracias estatais e/ou internacionais, inserindo-se, nacional e localmente, no cenário da democratização da gestão educacional (DÍEZ-HOCHLEITNER, 1990).

Embora o Plano Decenal de Educação para Todos (PDET) (1993-2003) tenha resultado de compromissos internacionalmente assumidos pelo Brasil, notadamente no âmbito da Conferência Mundial sobre Educação para Todos, realizada em Jomtien, em 1990, exprimiu, embrionariamente, repercussões do modelo de planejamento participativo, na medida em que pressupôs protagonismos de atores sociais relativos aos estados e municípios que se dispuseram à elaboração de sua versão decenal local. De qualquer modo, sem legitimidade social suficiente, este plano também perdeu importância, à época, no interior do próprio Ministério da 
Educação e do Desporto (MEC), sendo definitivamente ofuscado em face das discussões sobre a construção de um novo plano decenal, o então PNE 2001-2010 (SAVIANI, 1999, VIEIRA, 2000).

Será justamente com os I e II PNE - respectivamente, 2001-2010 e 2014-2024 - que os processos participativos se tornarão mais evidentes e produtivos, não apenas em termos da elaboração de suas respectivas configurações estaduais e municipais, mas, igualmente, no âmbito da própria proposta nacional (SOUZA; MENEZES, 2015). Em que pese estes dois planos terem mobilizado ampla discussão nacional, regional e local, na sua versão aprovada pelo Congresso o primeiro veio a espelhar a hegemonia da estrutura, objetivos e metas da proposta governamental apresentada, pouco refletindo a proposta da sociedade civil (BORDIGNON, 2014; SOUZA; DUARTE, 2014), enquanto que o segundo plano sequer veio a ter a proposta elaborada pela sociedade civil convertida em PL, transitando no Congresso apenas aquela de autoria do governo (BORDIGNON, 2014; OLIVEIRA; ARAÚJO, 2014).

Em larga medida, o PNE 2001-2010 já nasceu condenado à desventura, quer pelos vetos presidenciais que recebeu, que impactaram, em especial, o Ensino Superior, quer pela não previsão de fontes e recursos suficientes ao seu financiamento, quer em função dos problemas relativos à sua estruturação como, por exemplo, o excessivo número de objetivos, metas e diretrizes (DAVIES, 2001; DOURADO, 2010, VALENTE, 2001). Não obstante o fato de que apenas parte reduzida das metas deste plano vieram a ser alcançadas ou encaminhadas, é possível afirmar que o seu maior legado seja simbólico, consistindo numa espécie de aprendizado sócio-político, já que possibilitou a retomada dos processos participativos na formulação das políticas educacionais no país (AGUIAR, 2010; MARTINS, 2012), presentemente suspensos.

A experiência relativa ao insucesso do PNE 2001-2010 levou a muitas expectativas em torno da elaboração de um novo instrumento de planejamento que, três anos após o término da vigência deste primeiro plano, veio a ser aprovado, agora com referência ao decênio 2014-2020. Embora relativamente distante dos anseios da sociedade registrados na proposta final da Conferência Nacional de Educação (CONAE), em 2010, este novo PNE, desta vez assentado em um quantitativo exequível de 20 metas com prazos mensuráveis, veio a exprimir alguns avanços no seu texto, como a ampliação do investimento público em Educação, no seu décimo ano, para o patamar de $10 \%$ do Produto Interno Bruto (PIB), assim como a previsão de criação e articulação de um Sistema Nacional de Educação (SNE) em regime de colaboração, entre outros importante pontos (DOURADO, 2018; LUCE; FARENZEMA, 2015). 
Contudo, presentemente, restando apenas quatro anos para o término de vigência do PNE 2014-2024, tudo indica que estamos a frente de mais um plano de Educação em ruína, mostra do descumprimento de mais uma lei nesta área das políticas sociais. Sem poder considerar aqui o leque amplo de políticas dos governos nacional e infranacionais cuja dinâmica vem desfavorecendo sobremaneira o cumprimento das metas deste plano, como também as diversas formas de omissão de muitos desses governos, mas apenas evocando a aprovação do Novo Regime Fiscal (NRF), consubstanciado na Emenda Constitucional (EC) n ${ }^{\circ}$ 95, de 15 de dezembro de 2016 - que congelou gastos e investimentos (despesas primárias), em particular na área das políticas sociais -, há de se supor um novo estrépito no campo do planejamento educacional. A desvinculação do percentual mínimo de gasto em Manutenção e Desenvolvimento do Ensino (MDE) promovido por esta EC veio a comprometer diretamente a Meta 20 do PNE, não apenas do ponto de vista da extinção da possibilidade de ampliação do investimento público em Educação, mas em termos do esvaziamento das condições basais para o financiamento das demais metas, inviabilizando, inclusive, um próximo PNE, já que os efeitos desta EC se estenderão por 20 anos, até 2036 (AMARAL, 2016; 2017).

De fato, o Relatório do $3^{\circ}$ ciclo de monitoramento das metas do PNE, divulgado no início de julho deste ano (INEP, 2020), sinaliza que, até o presente momento, das 20 metas previstas, apenas uma única (5\%) veio a ser atingida, além do fato de ter ocorrido retrocesso nos números relativos aos gastos em Educação e à Educação em tempo integral. Trata-se de Meta 13, relativa à proporção de mestres e doutores em efetivo exercício na docência da Educação Superior que, antecipando-se aos $75 \%$ previstos para 2024, e também superando este objetivo, já registrava, desde o ano de 2018 , o percentual de $81,3 \%$, mas em meio ao reconhecimento deste mesmo relatório em torno da existência de significativas desigualdades entre territórios, instituições e docentes. Quanto ao restante das metas, $20 \%$ foram parcialmente atingidas (Ensino Fundamental, Educação Especial, Aprendizado na idade certa e Pós-graduação), $45 \%$ não foram, de fato, atingidas (Educação Infantil, Ensino Médio, Alfabetização, Educação de Jovens Adultos - EJA integrada à Educação Profissional, Formação de Professores, Salário do professor, Plano de carreira do professor, Gestão Democrática e Financiamento da Educação), e $30 \%$, até o presente momento, ainda não foram atingidas (Educação em tempo integral, Escolaridade da população adulta, Analfabetismo dos adultos, Educação Profissional, Educação Superior e Pós-graduação de professores).

Da pluralidade temática deste número de Ensaio assomam dois importantes trabalhos que diretamente remetem ao PNE em questão, que buscam depreender, por meio da realização de estudo de natureza bibliográfica e documental, os sentidos explícitos e implícitos atribuídos a certos conceitos constantes do 
conjunto de objetivos que serviram à definição deste instrumento de planejamento. Um primeiro artigo, de autoria de Jhonny David Echalar, Daniela da Costa Britto Pereira Lima e João Ferreira de Oliveira (Plano Nacional de Educação (2014-2024) - O uso da inovação como subsídio estratégico para a Educação Superior), toma por análise o próprio PNE 2014-2024, com foco no conceito de inovação e suas relações com as decisões deste plano relacionadas ao Ensino Superior, sinalizando, entre outros aspectos, o contexto de cortes orçamentários e de redução dos recursos para a pesquisa, desenvolvimento e inovação, também em decorrência da EC 95/2016, anteriormente mencionada. Já o artigo de Jorge Najjar, Marcelo Mocarzel e Karine Morgan (Os Planos Municipais de Educação do Estado do Rio de Janeiro: um mapeamento de metas, estratégias e desafios), enfoca a configuração local deste PNE, nomeadamente em termos dos Planos Municipais de Educação (PME) do estado do Rio de Janeiro, examinando-a nas decisões de 89 destes planos a partir de três conceitos centrais, a saber, Gênero, Educação em Tempo Integral e Qualidade.

Embora os demais estudos deste número de Ensaio não tratem diretamente sobre a materialização do planejamento da Educação no Brasil em planos decenais, como no caso do PNE 2014-2024, aludem importantes temáticas relacionadas aos níveis de Educação contemplados por este plano, como o Ensino Superior e a Educação Básica, seja em termos da realidade brasileira, seja evocando contextos internacionais.

Na esfera do Ensino Superior no Brasil, dois estudos se voltam para a problemática da avaliação institucional externa e interna, enquanto que um terceiro trabalho discute, em específico, a avaliação da eficiência de gastos nas instituições de Ensino Superior. No campo da avaliação institucional, Camila Henriques de Paula e Fernanda Maria de Almeida (O programa Reuni e o desempenho das Ifes brasileiras) analisam possíveis diferenças e influências do Programa de Apoio a Planos de Reestruturação e Expansão das Universidades Federais (Reuni) em relação à evolução dos indicadores de desempenho obtidos pelas Instituições Federais de Ensino Superior (Ifes) no país, enquanto que Nara Maria Emanuelli Magalhães e Cláudia Medianeira Cruz Rodrigues (A cultura de avaliação da Universidade Federal do Rio Grande do Sul (UFRGS): entre a avaliação externa e a autoavaliação) evidenciam a trajetória desta avaliação na UFRGS, isto por meio da efetuação de entrevistas com os gestores que protagonizaram tal processo ao longo do período 2000-2016. Por seu turno, o artigo de David Daniel Hammes Junior, Leonardo Flach e Luísa Karam de Mattos (The efficiency of public expenditure on Higher Education: a study with Brazilian Federal Universities/A eficiência do gasto público em Ensino Superior: um estudo com universidades federais brasileiras), discute a especificidade da avaliação da eficiência dos gastos 
públicos nas universidades federais brasileiras, cobrindo o período (2013-2017), lançando mão de recursos analíticos como a Análise Envoltória de Dados (DEA) e um modelo de regressão truncado.

Tendo como princípio modulador das análises o direito universal à Educação, a Educação Básica no país é abrangida no presente número de Ensaio em dois artigos, tanto de modo específico, com foco em uma das suas etapas, como também sob perspectiva mais geral, neste sentido problematizando-a sob a ótica dos seus componentes ao nível dos sistemas de ensino. No primeiro caso, Suzana Gomes Lopes, Isabel Matilde de Carvalho Xavier e Alexandre Leite dos Santos Silva (Rendimento escolar: um estudo comparativo entre alunos da área urbana e da área rural em uma escola pública do Piauí) indagam a respeito das influências socioeconômicas e escolares que incidem sobre o rendimento escolar de alunos do $6^{\circ}$ ano do Ensino Fundamental de zonas rurais e urbanas, tendo como campo de estudo uma escola municipal pública do estado do Piauí, e como fonte de dados os registros escolares, a aplicação de questionários e a realização de entrevistas. O segundo estudo, de autoria de Cândido Alberto Gomes (Escola de qualidade para todos revisitada: desfolhando as camadas da cebola), de caráter bibliográfico, com consulta a amplas bases/portais eletrônicos de dados, leva a efeito reflexões de cunho sociológico em torno da complexidade dos sistemas educacionais, realçando componentes como a seletividade, as questões de gênero, a administração, os currículos, os efeitos da escola, a sala de aula e o professor.

Coerentemente ao perfil que há muito vem perseguindo, Ensaio também não perde de vista neste número a sustentação do valor da Educação internacional, seja para a difusão global do conhecimento relativo aos países alvos dos artigos publicados, seja de modo a contribuir, em particular, para a reflexão da Educação brasileira, contribuindo para a problematização e relativização dos aspectos que constituem a nossa identidade e, com isto, concorrendo para o abandono dos léxicos dominantes, dos determinismos e das preconcepções, de forma a melhor possibilitar o conhecimento sobre o nosso próprio contexto e identidade sociocultural (BADIE; HERMET, 1993). Nestes termos, questões relativas às realidades do Ensino Superior atinentes a países como a China, Colômbia e Equador são abordadas, respectivamente, pelos trabalhos de Danilo de Melo Costa e Qiang Zha (Chinese Higher Education: The role of the economy and Projects 211/985 for system expansion/Educação Superior Chinesa: o papel da economia e dos projetos 211/985 para a expansão do sistema), de Sonia Restrepo-Palacio e Yasbley de María Segovia Cifuentes (Diseño y validación de un instrumento de evaluación de la competencia digital en Educación Superior/Desenho e validação de um instrumento para avaliação da competência digital no Ensino Superior), e, ainda, de Alex Estrada García (Los principios de la complejidad y su aporte 
al proceso de enseñanza/Os princípios da complexidade e sua contribuição ao processo de Ensino). Na esfera da Educação Básica, países como a África do Sul e, de modo conjunto, Brasil, México, Guatemala e Chile, são alvo das pesquisas de Thirusellvan Vandeyar (A window to teachers' ICT practices: Discerning between teaching and the complex science of pedagogy/Uma janela para as práticas de TIC dos professores: discernimento entre o Ensino e a complexa ciência da pedagogia) e de Ana Maria Eyng e João Casqueira Cardoso (Direitos da infância em contextos de necessidades humanitárias: fatores de risco e demandas educativas).

Como o leitor pode observar, o Ensino Superior e a Educação Básica constituem o grande proscênio deste número de Ensaio, no e pelo qual realidades plurais nacionais e internacionais hasteiam-se, trazendo à vista questões caras à Educação contemporânea. Resta-nos, pois, os votos de uma promissora consulta e produtiva leitura.

\section{Post Scriptum}

No instante final da publicação eletrônica e impressa deste número de Ensaio, fomos informados que um dos seus autores, Jorge Najjar, nos deixou, mesmo antes de poder se orgulhar da concretização editorial de mais um dos seus importantes trabalhos no campo da Educação. Professor, pesquisador, gestor, conselheiro, articulador e, sobretudo, companheiro de luta em torno dos mais nobres ideais educacionais, decerto, deixa inconsolável saudade...

\section{Referências}

AGUIAR, M. A. S. Avaliação do Plano Nacional de Educação 2001-2009: questões para reflexão. Educação \& Sociedade, Campinas, v. 31, n. 112, p. 707-727, jul./set. 2010. https://doi.org/10.1590/S0101-73302010000300004

AMARAL, N. C. Com a PEC 241/55 (EC 95) haverá prioridade para cumprir as metas do PNE (2014-2024)? Revista Brasileira de Educação, Rio de Janeiro, v. 22, n. 71, p. 1-25, out. 2017. https://doi.org/10.1590/s141324782017227145

AMARAL, N. C. PEC 241/55: a "morte" do PNE (2014-2024) e o poder de diminuição dos recursos educacionais. Revista Brasileira de Política e Administração da Educação, Goiânia, v. 32, n. 3, p. 653-673, set./dez. 2016. https://doi.org/10.21573/vol32n32016.70262

BADIE, B.; HERMET, G. Política comparada. México, DF: Fundo de Cultura Económica, 1993. 
BORDIGNON, G. Planos de governo e políticas de estado: muitos planos, pouco planejamento. In: SOUZA, D. B.; MARTINS, A. M. (orgs.). Planos de Educação no Brasil: planejamentos, políticas, práticas. São Paulo: Loyola, 2014. p. 29-53.

CURY, C. R. J. Por um Plano Nacional de Educação: nacional, federativo, democrático e efetivo. Revista Brasileira de Administração da Educação, Porto Alegre, v. 25, n. 1, p. 13-30, 2009. https://doi.org/10.21573/vol25n12009.19325

DAVIES, N. Plano Nacional de Educação: muito discurso, nenhum recurso. Universidade e Sociedade, São Paulo, v. 11, n. 25, p. 29-39, dez. 2001. Disponível em: http://www.redefinanciamento.ufpr.br/antigo/nic8.htm. Acesso em: 29 jul. 2020.

DÍEZ-HOCHLEITNER, R. D. Reforma y planificación de la educación. Actualidad Docente, Madrid, n. 123, p. 32-36, fev. 1990.

DOURADO, L. F. A institucionalização do Sistema Nacional de Educação e o Plano Nacional de Educação: proposições e disputas. Educação \& Sociedade, Campinas, v. 39, n. 143, p. 477-498, abr.jun. 2018. https://doi.org/10.1590/es0101-73302018203079

DOURADO, L. F. Avaliação do Plano Nacional de Educação 2001-2009: questões estruturais e conjunturais de uma política. Educação \& Sociedade, Campinas, v. 31, n. 112, p. 677-705, jul./set. 2010. https://doi.org/10.1590/S0101-73302010000300003

FUENTES PÉREZ, P. Hacia un concepto de planificación de la educación. Anales de Pedagogía, Murcia, n. 4, p. 89-102, 1986. Disponível em: http://revistas.um.es/ analespedagogia/article/download/288241/209421. Acesso em: 2 ago. 2020.

GALEANO, E. As veias abertas da América Latina. 24. ed. Rio de Janeiro: Paz e Terra, 1987.

HORTA, J. S. B. Liberalismo, tecnocracia e planejamento educacional no Brasil: uma contribuição à história da educação brasileira no período de 1930-1970. São Paulo: Cortez; Campinas: Autores Associados, 1982.

INSTITUTO NACIONAL DE ESTUDOS E PESQUISAS EDUCACIONAIS ANIISIO TEIXEIRA - INEP. Relatório do $3^{\circ}$ ciclo de monitoramento das metas do Plano Nacional de Educação - 2020. Brasília, DF: MEC/INEP, 2020. Disponível em: http://portal.inep.gov.br/informacao-da-publicacao/-/asset_ publisher/6JYIsGMAMkW1/document/id/6935276. Acesso em: 29 jul. 2020.

JASPERS, K. Iniciação filosófica. Lisboa: Guimarães, 1987. 
KHÔI, L. T. Planificación de la educación, historia de la. In: Huesen, T.; Postlethwaite, T. N. (dir.), Enciclopedia internacional de la educación. Madrid: MEC; Editorial Vicens-Vives, 1992. v. 8, p. 4.623-4.625.

LUCE, M. B.; FARENZENA, N. Uma contribuição ao movimento instituinte do Sistema Nacional de Educação. Revista Brasileira de Política e Administração da Educação, Porto Alegre, v. 31, n. 2, p. 427-449, maio/ ago. 2015. https://doi.org/10.21573/vol3 $\ln 22015.61738$

MARTINS, P. S. Planejamento e plano nacional de educação. Cadernos Aslegis, Brasília, DF, n. 39, p. 91-118, jan./abr. 2012.

MEYER, J. W.; RAMIREZ, F. O.; SOYSAL, Y. N. World expansion of mass education, 1870-1980. Sociology of Education, Washington, v. 65, n. 2, p. 128-149, apr. 1992. https://doi.org/10.2307/2112679

OLIVEIRA, D. A.; ARAÚJO, H. Educação entre os planos de governo e as políticas de Estado: o foco no financiamento e a questão docente. In: SOUZA, D. B.; MARTINS, A. M. (org.). Planos de educação no Brasil: planejamentos, políticas, práticas. São Paulo: Loyola, 2014. p. 167-182.

PALMERO CÁMARA, M. C.; JIMÉNEZ EGUIZABAL, J. A. La administración y planificación del sistema educativo: una necesidad calculada. Educadores, Madrid, v. 18, n. 140, p. 741-751, nov./dic. 1986.

RUBIO MAYORAL, J. L. El papel de la planificación educativa en la extensión del Estado de Binestar. Cuestiones Pedagógicas: Revista de Ciencias de la Educación, Sevilla, n. 12, p. 67-80, 1996. Disponível em: http:/institucional.us.es/revistas/ cuestiones/12/art_6.pdf. Acesso em: 1 ago. 2020.

SAVIANI, D. Organização da educação nacional: sistema e Conselho Nacional de Educação, Plano e Fórum Nacional de Educação. Educação \& Sociedade, Campinas, v. 31, n. 112, p. 769-787, jul./set. 2010. https://doi.org/10.1590/S0101-73302010000300007

SAVIANI, D. Sistemas de ensino e planos de educação: o âmbito dos municípios. Educação \& Sociedade, Campinas, v. 20, n. 69, p. 119-136, dez. 1999. https://doi.org/10.1590/S0101-73301999000400006

SOUZA, D. B.; DUARTE, M. R. T. Planos de educação no Brasil: projeções do sistema nacional de educação e suas variantes subnacionais. In: SOUZA, D. B.; MARTINS, A. M. (org.). Planos de educação no Brasil: planejamentos, políticas, práticas. São Paulo: Loyola, 2014. p. 209-232. 
SOUZA, D. B.; MENEZES, J. S. S. Elaboração e aprovação de planos de educação no Brasil: do nacional ao local. Ensaio: Avaliação de Políticas Públicas em Educação, Rio de Janeiro, v. 23, n. 89, p. 901-936, out./dez. 2015. https://doi.org/10.1590/S0104-40362015000400005

VALENTE, I. Plano Nacional de Educação. Rio de Janeiro: DP\&A, 2001.

VIEIRA, S. L. Planos e políticas educacionais: das concepções às práticas no Brasil. In: SOUZA, D. B.; MARTINS, A. M. (orgs.). Planos de educação no Brasil: planejamentos, políticas, práticas. São Paulo: Loyola, 2014. p. 55-71.

VIEIRA, S. L. Política educacional em tempos de transição (1985-1995). Brasília, DF: Plano, 2000.

WEILER, H. N. Planificación de la educación: perspectiva general. In: Huesen, T; Postlethwaite, T. N. (dir.). Enciclopedia internacional de la educación. Madrid: MEC; Editorial Vicens-Vives, 1992. v. 8, p. 4.625-4.629.

\section{Informações do autor}

Donaldo Bello de Souza: Professor Titular no Departamento de Políticas Públicas, Avaliação e Gestão da Educação, da Faculdade de Educação da Universidade do Estado do Rio de Janeiro. Doutorado em Educação pela Universidade Federal do Rio de Janeiro. Pós-Doutorado em Políticas Educacionais Comparadas pela Facultad de Ciencias de la Educación da Universidad de Granada e em Política e Administração Educacional pela Faculdade de Psicologia e de Ciências da Educação da Universidade de Lisboa. Contato: donaldobello@gmail.com

iD https://orcid.org/0000-0002-9146-5254 